\title{
AN IMPROVED SUPPORT VECTOR REGRESSION AND ITS MODELLING OF MANOEUVRING PERFORMANCE IN MULTIDISCIPLINARY SHIP DESIGN OPTIMIZATION
}

\author{
Dongqin $\mathrm{Li}^{*}$, a , Philip A. Wilson ${ }^{* *}, \mathrm{~b}$, Zhiyong Jiang ${ }^{*}, \mathrm{c}$ \\ * School of Naval Architecture \& Ocean Engineering, Jiangsu University of Science and Technology, Zhenjiang, \\ Jiangsu, China, 212003 \\ ${ }^{* *}$ Faculty of Engineering and the Environment, University of Southampton, Southampton, UK, SO17 $1 B J$

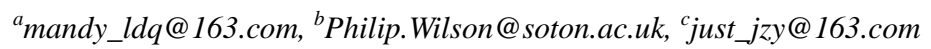

Abstract: In this paper, the combination of the Laplace loss function and Support Vector Regression (SVR) are presented for the estimation of manoeuvring performance in multidisciplinary ship design optimization, and a new SVR algorithm was proposed, which has only one parameter to control the errors and automatically minimized with $v$, and adds $b^{2} / 2$ to the item of confidence interval. It is shown that the proposed SVR algorithm in conjunction with the Laplace loss function can estimate the ship manoeuvring performance appropriately compared to the simulation results with Napa software and other approximation methods such as Artificial Neural Network (ANN) and classic SVR. In this article, we also gather enough ship information about the offshore support vessel; the Latin Hypercube Design is employed to explore the design space. Instead of requiring the evaluation of expensive simulation codes, we establish the metamedels of ship manoeuvring performance; all the numerical results show the effectiveness and practicability of the new approximation algorithms.

Key Words: Metamodel; Support Vector Machine; Multidisciplinary Design Optimization; Ship manoeuvring

List of symbols: 


$\begin{array}{llll}L_{p p} & \text { Length between perpendiculars } & C & \text { Penalty parameter } \\ B & \text { Breadth moulded } & \xi, \xi^{*} & \text { The parameters of classical SVR } \\ D & \text { Depth moulded } & \phi\left(x_{i}\right) \cdot \phi(x) & \text { The inner product of high-dimension space } \\ T & \text { Draught moulded } & K\left(x_{i}, x\right) & \text { The kernel function } \\ D W T & \text { The deadweight tonnage } & \left\{x_{i}, y_{i}\right\} & \text { The training data set } \\ w_{i} & \text { The weight factor } & \varepsilon & \text { Tube parameter for insensitive loss function } \\ \sigma^{2} & \text { Gaussian kernel parameter } & v & \text { The parameter of } \varepsilon\end{array}$

\section{Introduction}

In the ship design process, there is often more than one element; that is, there may be different disciplines which contribute to the ship design [1], such as structures, economics, or hydrodynamics. The disciplines may be studied with different software tools, or investigated by different teams of engineers. Due to these complexities, the ship design problem cannot be formulated simply as a single optimization statement. Therefore, it is necessary to improve the algorithm of Multidisciplinary Design Optimization (MDO) and its goal is to develop the methodology to coordinate different discipline optimizations, and achieve a design plan that optimizes all disciplines [2-4].

The development of ship design technology is dependent upon a cooperative, multidisciplinary design approach. To reduce the computational cost of computer-based simulations and analyses in ship design, a variety of metamodeling 
techniques have been developed[5-7], for instance Response Surface Model (RSM), kriging and Artificial Neural Network (ANN). Metamodel is a key element of the MDO. In this paper, a new simple and effective algorithm of Support Vector Machines (SVM) is proposed and used to establish the metamodels of ship manoeuvring performance in the Multidisciplinary Ship Design optimization.

\section{Improved Mathematical Model of $v$-SPL-SVR}

It is important to improve the accuracy and robustness performance of metamodeling techniques especially when the sample size becomes small and limited. The SVR algorithm aims at limited samples and has a good generalization performance as well as global optimal extremum which have been proved by many scholars [11]. Inspired by the reference [13], a modification of Single-parameter Lagrangian Support Vector Regression (SPL-SVR) [12] was proposed in this papar, called $v$-SPL-SVR. Given a set of data points, $\left\{\left(x_{1}, y_{1}\right),\left(x_{2}, y_{2}\right), \cdots,\left(x_{l}, y_{l}\right)\right\}$, such that $x_{i} \in R^{n}$ is an input and $y_{i} \in R^{1}$ is a target output, the primal problem is list as follows:

$$
\left\{\begin{array}{l}
\operatorname{Min} \frac{1}{2} w^{T} w+\frac{1}{2} b^{2}+C\left(v \varepsilon+\sum_{i=1}^{l}\left|\xi_{i}\right|\right) \\
\text { such that } \quad\left|y_{i}-w^{T} \phi\left(x_{i}\right)-b\right| \leq \varepsilon+\xi_{i} \\
\varepsilon \geq 0, \xi_{i} \geq 0, \quad 0 \leq v \leq 1, \quad i=1, \cdots, l
\end{array}\right.
$$

Here; $\frac{1}{2} w^{T} w$ is a term which characterizes the model complexity. $C$ is the penalty parameter, and training vectors $x_{i}$ are mapped into a higher (maybe infinite) dimensional space by the function $\phi$. The $\varepsilon$-insensitive loss function means that if $w^{T} \phi\left(x_{i}\right)$ is in the range of $y \pm \varepsilon$, no loss is considered. The formulations use 
parameters $C$ and $\varepsilon$ to apply a penalty to the optimization for points which were not correctly predicted.

As it is difficult to select an appropriate $\varepsilon$ for SPL-SVR, so here we introduce a new parameter $v$, which is an upper bound on the fraction of margin errors and a lower bound of the fraction of support vectors. Also the parameter $v$ lets one control the number of support vectors and training errors. For the constraints, we introduce multipliers $\alpha_{i}, \alpha_{i}^{*}, \eta_{i}, \beta$ and obtain the Lagrange function:

$$
\begin{aligned}
& L=\frac{1}{2}\left(w^{T} w+b^{2}\right)+C v \varepsilon+C \sum_{i=1}^{l}\left|\xi_{i}\right|-\sum_{i=1}^{l} \alpha_{i}\left[\varepsilon+\xi_{i}-y_{i}+w^{T} \phi\left(x_{i}\right)+b\right]- \\
& \sum_{i=1}^{l} \alpha_{i}^{*}\left[\varepsilon+\xi_{i}+y_{i}-w^{T} \phi\left(x_{i}\right)-b\right]-\sum_{i=1}^{l} \eta_{i} \cdot \xi_{i}-\beta \varepsilon
\end{aligned}
$$

It follows from the saddle point condition that the partial derivatives of $L$ with respect to the primal variables $\left(w, b, \xi_{i}, \varepsilon\right)$ have to vanish for optimality.

$$
\begin{aligned}
& \frac{\partial L}{\partial b}=b-\sum_{i=1}^{l}\left(\alpha_{i}-\alpha_{i}^{*}\right)=0 \\
& \frac{\partial L}{\partial w}=w-\sum_{i=1}^{l}\left(\alpha_{i}-\alpha_{i}^{*}\right) \cdot \phi\left(x_{i}\right)=0 \\
& \frac{\partial L}{\partial \xi_{i}}=C-\alpha_{i}-\alpha_{i}^{*}-\eta_{i}=0 \\
& \frac{\partial L}{\partial \varepsilon}=C v-\beta-\sum_{i=1}^{l}\left(\alpha_{i}+\alpha_{i}^{*}\right)=0
\end{aligned}
$$

A kernel function $K\left(x_{i}, x_{j}\right)=\left(\phi\left(x_{i}\right) \cdot \phi\left(x_{j}\right)\right)$ is introduced into the formula, which can map the nonlinear high-dimensional design space into linear low-dimensional 
design space with a Radial Basis Function (RBF) [14] is $K\left(x_{i} \cdot x_{j}\right)=\exp \left(-\beta\left\|x_{i}-x_{j}\right\|^{2}\right)$.The dual optimization problem is shown as follows:

$\left\{\begin{array}{l}\operatorname{Min} \frac{1}{2} \sum_{i, j=1}^{l}\left(\alpha_{i}-\alpha_{i}^{*}\right)\left(\alpha_{j}-\alpha_{j}^{*}\right)\left[K\left(x_{i} \cdot x_{j}\right)+1\right]-\sum_{i=1}^{l}\left(\alpha_{i}-\alpha_{i}^{*}\right) \cdot y_{i} \\ \text { such that } \quad\left(\alpha_{i}+\alpha_{i}^{*}\right) \leq C, \sum_{i=1}^{l}\left(\alpha_{i}+\alpha_{i}^{*}\right) \leq C v \\ \quad \alpha_{i}, \alpha_{i}^{*} \geq 0\end{array}\right.$

Compared to the SPL-SVR, there is no $\varepsilon$ in the objective function (7), which means we do not have to decide on the $\varepsilon$ for insensitive loss function before optimization. The above optimization problem can be stated as in a standard formulized quadratic programming.

$$
\begin{cases}\operatorname{Min} & \frac{1}{2} X^{T} H X+d^{T} X \\ \text { s.t. } & A X \leq C^{*}, \quad B X \leq C^{*} v, \quad X \geq 0\end{cases}
$$

Where, $X=\left[\begin{array}{l}\alpha \\ \alpha^{*}\end{array}\right]_{2 l \times 1}, H=\left[\begin{array}{cc}K & -K \\ -K & K\end{array}\right], \alpha^{(*)}=\left[\alpha_{1}^{(*)}, \alpha_{2}{ }^{(*)}, \cdots, \alpha_{l}^{(*)}\right]^{T}$, $C^{*}=[C, C, \cdots, C]_{1 \times l}{ }^{T}, \quad Y=\left[y_{1}, y_{2}, \cdots, y_{l}\right]^{T}, \quad B=[1,1, \cdots, 1]_{1 \times 2 l}, \quad d=\left[\begin{array}{c}-Y \\ +Y\end{array}\right]_{2 l \times 1}$, $A=\left[\begin{array}{cccccccc}1 & 0 & \cdots & 0 & 1 & 0 & \cdots & 0 \\ 0 & 1 & \cdots & 0 & 0 & 1 & \cdots & 0 \\ \cdots & \cdots & \cdots & \cdots & \cdots & \cdots & \cdots & \cdots \\ 0 & 0 & \cdots & 1 & 0 & 0 & \cdots & 1\end{array}\right]_{l \times 2 l} \quad K=\left[\begin{array}{cccc}K\left(x_{1}, x_{1}\right)+1 & K\left(x_{1}, x_{2}\right)+1 & \cdots & K\left(x_{1}, x_{l}\right)+1 \\ K\left(x_{2}, x_{1}\right)+1 & K\left(x_{2}, x_{2}\right)+1 & \cdots & K\left(x_{2}, x_{l}\right)+1 \\ \cdots & \cdots & \cdots & \cdots \\ K\left(x_{l}, x_{1}\right)+1 & K\left(x_{l}, x_{2}\right)+1 & \cdots & K\left(x_{l}, x_{l}\right)+1\end{array}\right]_{l \times l}$

Thus, the estimation function is calculated as follows:

$$
f(x)=\sum_{i=1}^{l}\left(\alpha_{i}-\alpha_{i}^{*}\right)\left(K\left(x_{i} \cdot x\right)+1\right)
$$

With this simpler algorithm, we can obtain the black box which describes the complicated mapping relation without knowing the connection between the dependent 
variables and independent variables. Therefore, this new algorithm is suitable for the construction of a ship manoeuvring approximation model in the multidisciplinary design optimization for the ship preliminary and early-stage design.

\section{Distribution of ship samples}

Before constructing the metamodels of ship manoeuvring performance, we need to gather plenty of ship information and select the training ship data set. Here, we choose Latin Hypercube Designs as the method of design of experiments. The Latin Hypercube method chooses points to maximize distance between design points with a constraint which maintains the even spacing between factor levels. At the same time, plenty of data measuring offshore support vessels were gathered from many shipping companies and design institutions. The distributions of the main principal characteristics are showed as Fig.1, in which the red points represent the 20 training ship data.
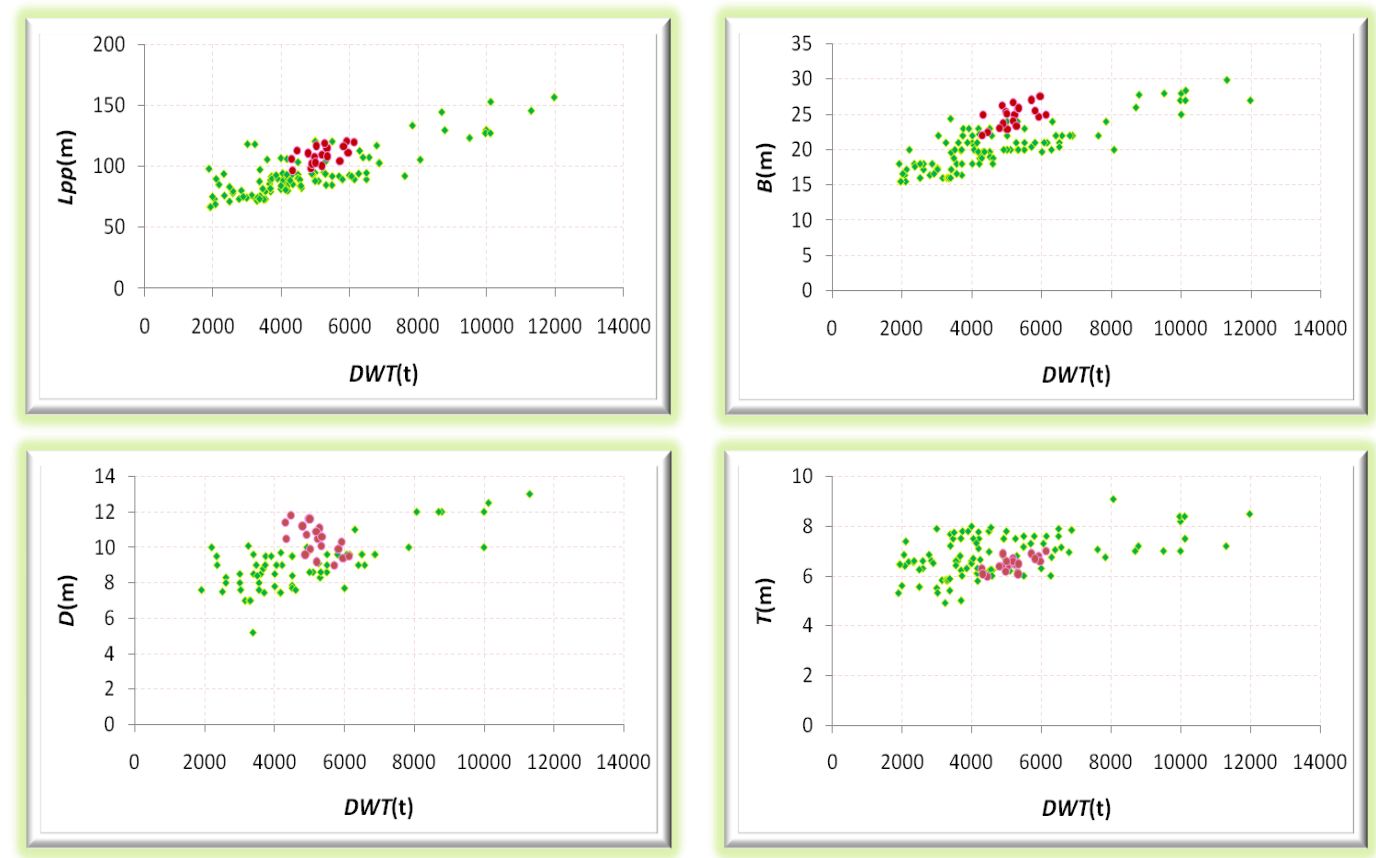

Fig. 1 Distribution of vessels' principal characteristics 


\section{Establishment of metamodels of ship manoeuvring performance}

As is well known, there are many variables which affect ship manoeuvring performance. Here, we chose the length between perpendiculars, breadth, depth, design draught, longitudinal centre of buoyancy, ship velocity and diameter of propeller as the main design variables, and the ship advance, tactical diameter, transfer, $10^{\circ} / 10^{\circ}$ first overshoot angle and $20^{\circ} / 20^{\circ}$ first overshoot angle as output variables.

We use the standard model-based calibration toolbox from commercial software Matlab to choose the 20 training data set with Latin Hypercube Design, which are listed in the Table 1.

Table 1 The design variables of 20 training ship data

\begin{tabular}{|c|c|c|c|c|c|c|c|}
\hline Ship & Length & Breadth & Depth & Draught & Velocity & $\begin{array}{l}\text { Propeller } \\
\text { diameter }\end{array}$ & $\begin{array}{c}\text { Longitudinal } \\
\text { centre } \\
\text { of buoyancy }\end{array}$ \\
\hline & $L_{p p} / m$ & $B / m$ & $D / m$ & $T / m$ & $V_{s} /$ Knot & $D_{p} / m$ & $L_{c b} / m$ \\
\hline 1 & 117.7 & 22.8 & 10.3 & 6.7 & 14.5 & 3.5 & 57.79 \\
\hline 2 & 113.0 & 22.4 & 11.8 & 6.0 & 14.5 & 3.4 & 57.25 \\
\hline 3 & 98.4 & 26.3 & 9.6 & 6.4 & 14.5 & 3.2 & 55.48 \\
\hline 4 & 102.1 & 23.7 & 10.7 & 6.9 & 14.5 & 3.5 & 48.31 \\
\hline 5 & 107.5 & 25.4 & 11.6 & 6.2 & 14.5 & 3.7 & 50.13 \\
\hline 6 & 105.7 & 22.0 & 11.4 & 6.3 & 14.5 & 3.3 & 52.78 \\
\hline 7 & 120.3 & 24.6 & 10.3 & 6.8 & 14.5 & 3.4 & 51.90 \\
\hline 8 & 109.4 & 25.0 & 10.5 & 6.5 & 14.5 & 3.7 & 59.06 \\
\hline 9 & 96.6 & 25.0 & 10.5 & 6.1 & 14.5 & 3.5 & 53.71 \\
\hline 10 & 111.2 & 27.6 & 9.4 & 6.6 & 14.5 & 3.3 & 47.43 \\
\hline 11 & 109.4 & 24.1 & 9.2 & 6.7 & 14.5 & 3.6 & 54.60 \\
\hline 12 & 114.8 & 25.9 & 10.1 & 6.1 & 14.5 & 3.6 & 53.49 \\
\hline 13 & 118.5 & 23.3 & 11.1 & 6.5 & 14.5 & 3.3 & 56.36 \\
\hline 14 & 103.9 & 27.1 & 9.0 & 6.9 & 14.5 & 3.5 & 58.18 \\
\hline 15 & 100.2 & 26.7 & 10.9 & 6.6 & 14.5 & 3.7 & 51.01 \\
\hline 16 & 115.9 & 25.5 & 9.9 & 6.7 & 14.5 & 3.6 & 56.90 \\
\hline 17 & 119.5 & 24.9 & 9.5 & 7 & 14.5 & 3.7 & 58.67 \\
\hline 18 & 110.7 & 23 & 11.2 & 6.4 & 14.5 & 3.4 & 54.35 \\
\hline
\end{tabular}




\begin{tabular}{cccccccc}
\hline 19 & 102.8 & 25.1 & 11.6 & 6.6 & 14.5 & 3.5 & 50.47 \\
20 & 108 & 25.9 & 10.6 & 6.5 & 14.5 & 3.5 & 53.03 \\
\hline
\end{tabular}

Before establishing the metamodels of seakeeping performance in Multidisciplinary Ship Design Optimization, we should first decide the calculation method for the ship manoeuvring performance of offshore support vessel. As the objective of this article is to develop a practical approximation model of ship manoeuvring performance in the hydrodynamic-based multidisciplinary design optimization at the early design stage, a practical calculation tool, based on the MMG (Ship Manoeuvring Mathematical Model Group) Model called Manoeuvring Manager from the commercial software NAPA, is used to compute the manoeuvring criteria. The ship hull of one training ship is shown in Fig.2; the simulation of turning circle manoeuvre is shown in Fig.3; the simulations of Zigzag test is shown in Fig.4

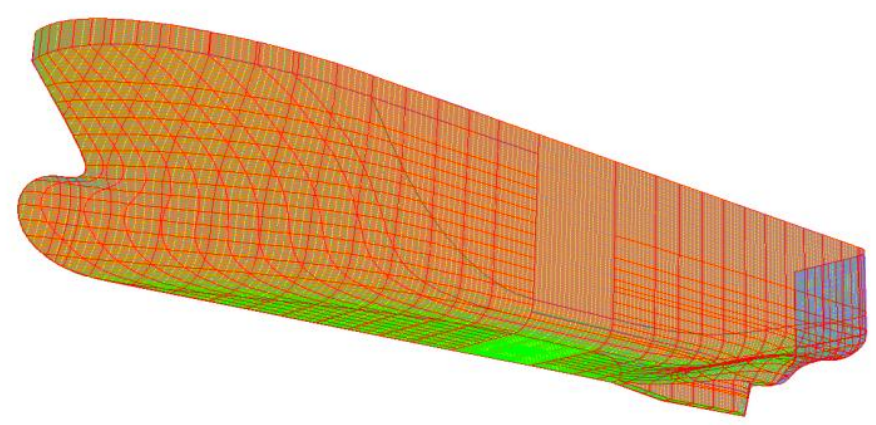

Fig. 2 3D lay-out of ship hull

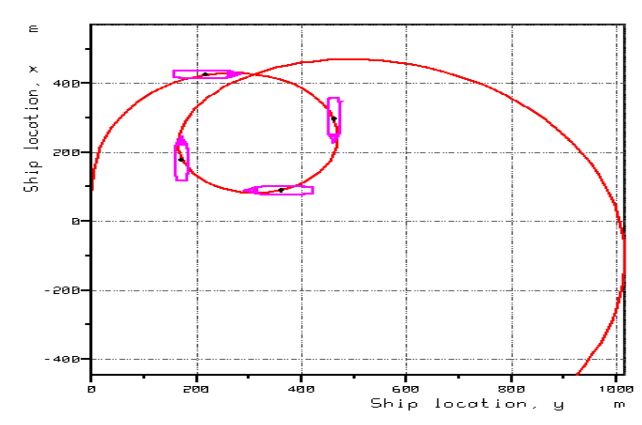

Fig. 3 The simulation of turning circle manoeuvre

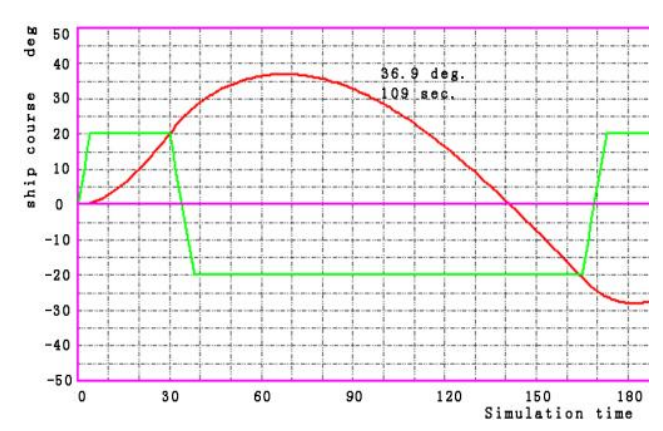

Fig. 4 The simulation of Zigzag test $10^{\circ} / 10^{\circ}$ 
The criteria described in IMO Resolution A.751 (18) (1993) [15], are commonly used to judge the manoeuvring characteristics of a vessel. Here the advance, tactical diameter, transfer, $10^{\circ} / 10^{\circ}$ first overshoot angle and $20^{\circ} / 20^{\circ}$ first overshoot angle are chosen as manoeuvring criteria to evaluate the performance for the offshore support vessel. These calculated manoeuvring criteria of 20 ship types are listed in Table 2.

Table 2 Calculated manoeuvring criteria of 15 training ship data

\begin{tabular}{|c|c|c|c|c|c|}
\hline Ship type & Advance & $\begin{array}{l}\text { Tactical } \\
\text { diameter }\end{array}$ & Transfer & $\begin{array}{c}10^{\circ} / 10^{\circ} \text { first } \\
\text { overshoot } \\
\text { angle }\end{array}$ & $\begin{array}{c}20^{\circ} / 20^{\circ} \text { first } \\
\text { overshoot } \\
\text { angle }\end{array}$ \\
\hline Unit & $\mathrm{m}$ & $\mathrm{m}$ & $\mathrm{m}$ & $\circ$ & $\circ$ \\
\hline 1 & 259.8 & 232.6 & 81.9 & 9.7 & 22.3 \\
\hline 2 & 235.8 & 246.6 & 96.2 & 10.2 & 19.9 \\
\hline 3 & 197.7 & 188.3 & 53.9 & 11.5 & 21.1 \\
\hline 4 & 205.3 & 196.6 & 63.6 & 11.4 & 20.9 \\
\hline 5 & 219.6 & 209.2 & 65.6 & 12.0 & 20.5 \\
\hline 6 & 215.8 & 207.5 & 70.9 & 9.5 & 17.6 \\
\hline 7 & 237.5 & 231.8 & 77.1 & 10.7 & 17.4 \\
\hline 8 & 223.9 & 214.4 & 69.8 & 11.2 & 19.6 \\
\hline 9 & 195.4 & 183.5 & 54.9 & 11.4 & 21.0 \\
\hline 10 & 229.6 & 219.0 & 69.6 & 11.3 & 22.5 \\
\hline 11 & 244.8 & 232.3 & 80.6 & 8.5 & 14.4 \\
\hline 12 & 240.1 & 227.4 & 76.7 & 11.3 & 18.4 \\
\hline 13 & 247.1 & 241.2 & 87.3 & 9.0 & 18.0 \\
\hline 14 & 208.8 & 201.3 & 59.1 & 12.0 & 21.6 \\
\hline 15 & 202.0 & 193.0 & 56.2 & 11.7 & 20.1 \\
\hline 16 & 251.3 & 242.7 & 78.7 & 11.5 & 20.6 \\
\hline 17 & 262.2 & 237.5 & 88.5 & 10.6 & 18.9 \\
\hline 18 & 250.0 & 214.1 & 69.5 & 11.6 & 20.8 \\
\hline 19 & 213.3 & 199.0 & 62.3 & 11.2 & 20.2 \\
\hline 20 & 228.0 & 215.3 & 81.6 & 9.5 & 17.1 \\
\hline
\end{tabular}

Using these calculated values of manoeuvring criteria, the benchmarking methodology presented in this article can be used to establish metamodels of manoeuvring performance of offshore support vessels in the multidisciplinary ship design optimization without running expensive model tests or time consuming CFD 
calculations. Here, the programs are written in Matlab and the metamodels of ship manoeuvring performance are constructed with the proposed $v$-SPL-SVR. We separate two cases to demonstrate the efficiency of the new proposed Support Vector Regression algorithm.

Case 1: At first, ship types 1 to 10 were selected as training data sets and ship types 11 to 20 as test data sets. The calculation results were compared with Manoeuvring Manager, ANN, classic SVR and SPL-SVR which were shown as Fig.5. Here the calculation result for advance is listed in Table 3 for instance. The Relative Error (RE) and Mean Relative Error (MRE) are applied as performance indices: $R E=\frac{y_{i}-y_{i}^{*}}{y_{i}}, M R E=\frac{1}{n} \sum_{i=1}^{n}\left|\frac{y_{i}-y_{i}^{*}}{y_{i}}\right|$, where $y_{i}$ is the real value and $y_{i}^{*}$ is the predicted value.

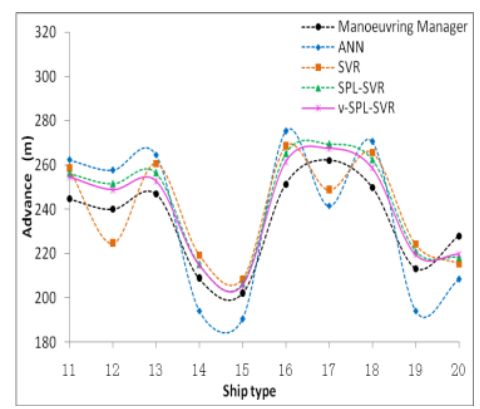

(a) Advance

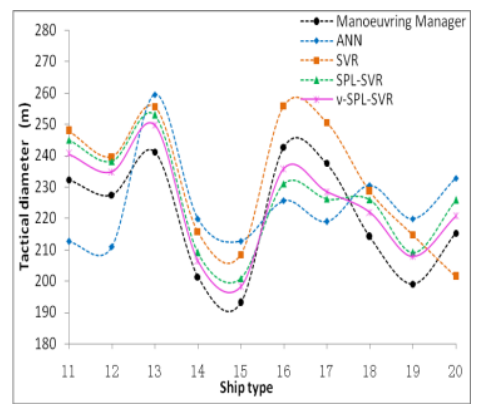

(b) Tactical diameter

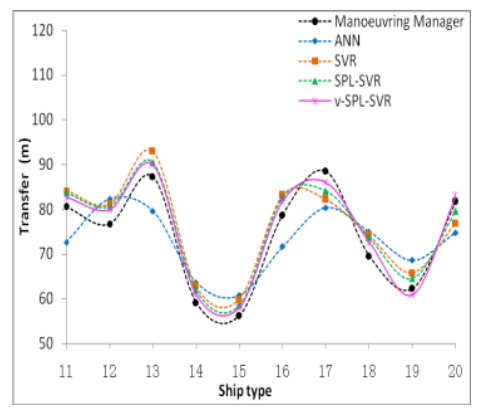

(c) Transfer

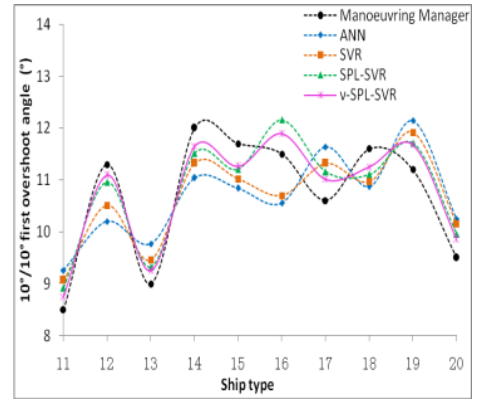

(d) $10^{\circ} / 10^{\circ}$ first overshoot angle

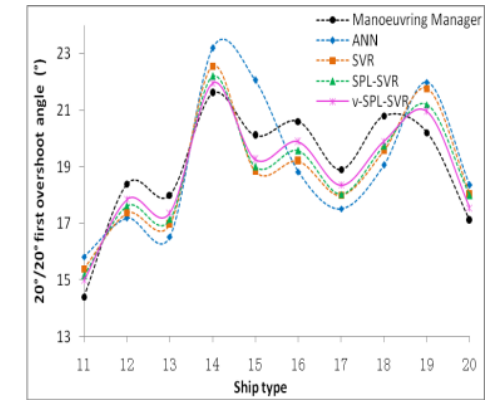

(e) $20^{\circ} / 20^{\circ}$ first overshoot angle

Fig.5 The result of Case 1 for ship type 11 to 20 
Table 3 Calculation result with Relative Error (RE) for Advance

\begin{tabular}{ccccccccccc}
\hline \multirow{2}{*}{$\begin{array}{c}\text { Ship type } \\
\text { number }\end{array}$} & Manager & \multicolumn{2}{c}{ ANN } & \multicolumn{2}{c}{ SVR } & SPL-SVR & \multicolumn{1}{c}{-SPL-SVR } \\
\cline { 2 - 10 } & & Value & Relative & Value & Relative & Value & Relative & Value & Relative \\
& $(\mathbf{m})$ & $(\mathbf{m})$ & Error & $(\mathbf{m})$ & Error & $(\mathbf{m})$ & Error & $(\mathbf{m})$ & Error \\
\hline 10 & 244.8 & 262.3 & $7.14 \%$ & 258.3 & $5.53 \%$ & 256.2 & $4.66 \%$ & 254.6 & $3.99 \%$ \\
11 & 240.1 & 257.6 & $7.28 \%$ & 224.6 & $-6.44 \%$ & 251.5 & $4.75 \%$ & 248.8 & $3.62 \%$ \\
12 & 247.1 & 264.6 & $7.07 \%$ & 260.6 & $5.48 \%$ & 256.5 & $3.81 \%$ & 252.9 & $2.34 \%$ \\
13 & 208.8 & 194.3 & $-6.96 \%$ & 219.3 & $5.05 \%$ & 215.2 & $3.07 \%$ & 214.8 & $2.87 \%$ \\
14 & 202.0 & 190.5 & $-5.71 \%$ & 208.5 & $3.24 \%$ & 206.4 & $2.18 \%$ & 205.8 & $1.87 \%$ \\
15 & 251.3 & 275.3 & $9.54 \%$ & 268.3 & $6.78 \%$ & 265.2 & $5.53 \%$ & 261.5 & $4.04 \%$ \\
16 & 262.2 & 241.6 & $-7.87 \%$ & 248.6 & $-5.17 \%$ & 269.5 & $2.79 \%$ & 267.5 & $2.02 \%$ \\
17 & 250.0 & 270.6 & $8.23 \%$ & 265.6 & $6.25 \%$ & 262.5 & $5.00 \%$ & 258.8 & $3.52 \%$ \\
18 & 213.3 & 194.3 & $-8.92 \%$ & 224.3 & $5.17 \%$ & 221.2 & $3.71 \%$ & 219.5 & $2.93 \%$ \\
19 & 228.0 & 208.5 & $-8.57 \%$ & 215.5 & $-5.47 \%$ & 218.4 & $-4.21 \%$ & 219.7 & $-3.62 \%$ \\
20 & 244.8 & 262.3 & $7.14 \%$ & 258.3 & $5.53 \%$ & 256.2 & $4.66 \%$ & 254.6 & $3.99 \%$ \\
\hline
\end{tabular}

Case 2: Then similarly, ship types 11 to 20 were selected as training data sets and ship types 1 to 10 as test data sets. The results were shown as Fig.6. As an example of calculated data, the result for $10^{\circ} / 10^{\circ}$ first overshoot angle is listed in Table 4 .

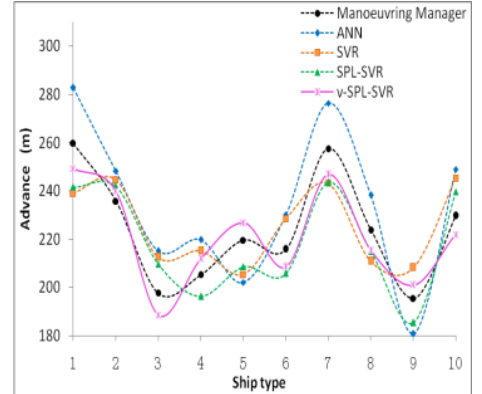

(a) Advance

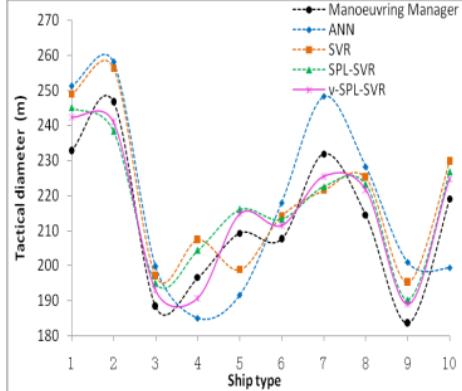

(b) Tactical diameter

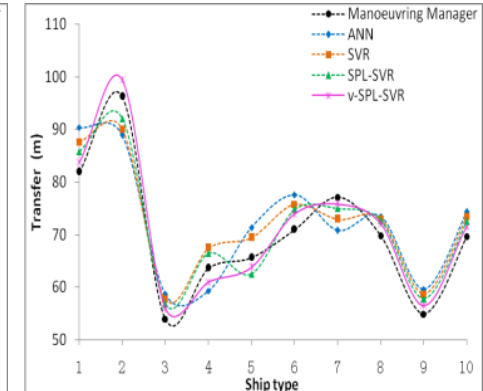

(c) Transfer

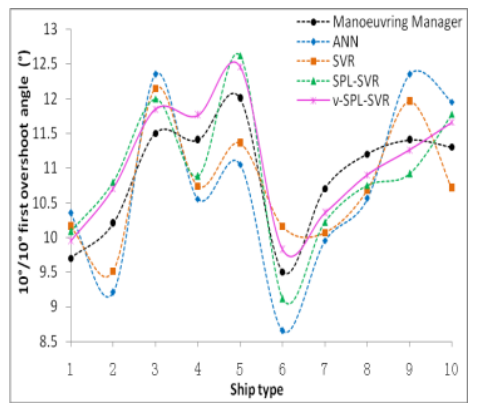

(d) $10^{\circ} / 10^{\circ}$ first overshoot angle

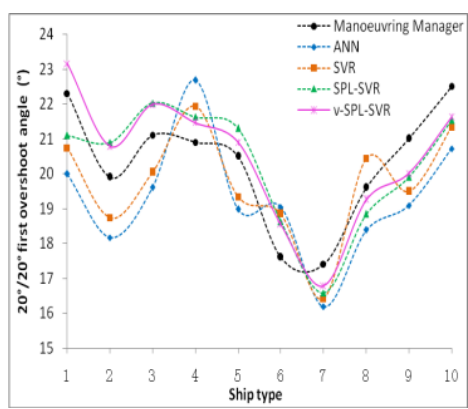

(e) $20^{\circ} / 20^{\circ}$ first overshoot angle

Fig.6 The result of Case 2 for ship type 1 to 10 
Table 4 Calculation result with Relative Error (RE) for $10^{\circ} / 10^{\circ}$ first overshoot angle

\begin{tabular}{cccccccccc}
\hline \multirow{2}{*}{$\begin{array}{c}\text { Ship type } \\
\text { number }\end{array}$} & $\begin{array}{c}\text { Manoeuvring } \\
\text { Manager }\end{array}$ & \multicolumn{2}{c}{ ANN } & \multicolumn{2}{c}{ SVR } & \multicolumn{2}{c}{ SPL-SVR } & \multicolumn{1}{c}{$v$-SPL-SVR } \\
\cline { 3 - 10 } & $(\mathbf{m})$ & $\begin{array}{c}\text { Value } \\
(\mathbf{m})\end{array}$ & $\begin{array}{c}\text { Relative } \\
\text { Error }\end{array}$ & $\begin{array}{c}\text { Value } \\
(\mathbf{m})\end{array}$ & $\begin{array}{c}\text { Relative } \\
\text { Error }\end{array}$ & $\begin{array}{c}\text { Value } \\
(\mathbf{m})\end{array}$ & $\begin{array}{c}\text { Relative } \\
\text { Error }\end{array}$ & $\begin{array}{c}\text { Value } \\
(\mathbf{m})\end{array}$ & $\begin{array}{c}\text { Relative } \\
\text { Error }\end{array}$ \\
\hline 1 & 9.7 & 10.3 & $6.69 \%$ & 10.2 & $4.69 \%$ & 10.1 & $3.97 \%$ & 9.9 & $2.56 \%$ \\
2 & 10.2 & 9.2 & $-9.75 \%$ & 9.5 & $-6.71 \%$ & 10.8 & $5.86 \%$ & 10.7 & $4.95 \%$ \\
3 & 11.5 & 12.3 & $7.38 \%$ & 12.1 & $5.64 \%$ & 12.0 & $4.28 \%$ & 11.8 & $3.01 \%$ \\
4 & 11.4 & 10.5 & $-7.47 \%$ & 10.7 & $-5.83 \%$ & 10.9 & $-4.55 \%$ & 11.8 & $3.16 \%$ \\
5 & 12 & 11.0 & $-7.93 \%$ & 11.4 & $-5.38 \%$ & 12.6 & $5.15 \%$ & 12.5 & $3.81 \%$ \\
6 & 9.5 & 8.7 & $-8.94 \%$ & 10.2 & $6.91 \%$ & 9.1 & $-4.05 \%$ & 9.8 & $3.36 \%$ \\
7 & 10.7 & 9.9 & $-7.02 \%$ & 10.1 & $-5.93 \%$ & 10.2 & $-4.53 \%$ & 10.3 & $-3.28 \%$ \\
8 & 11.2 & 10.6 & $-5.74 \%$ & 10.7 & $-4.64 \%$ & 10.8 & $-4.01 \%$ & 10.9 & $-2.70 \%$ \\
9 & 11.4 & 12.3 & $8.32 \%$ & 12.0 & $4.86 \%$ & 10.9 & $-4.25 \%$ & 11.3 & $-1.25 \%$ \\
10 & 11.3 & 12.0 & $5.76 \%$ & 10.7 & $-5.25 \%$ & 11.8 & $4.18 \%$ & 11.7 & $3.17 \%$ \\
\hline
\end{tabular}

The MRE comparison for the five manoeuvring criteria in two cases is listed in Table

5. From the results, we can see that the maximum MRE for $v$-SPL-SVR in Case 1 is $3.34 \%$ and the minimum MRE is $3.08 \%$; the maximum MRE for $v$-SPL-SVR in Case 2 is $3.63 \%$ and the minimum MRE is $2.83 \%$. Obviously, if the training ships data sets, the kernel parameters and the calculation method for manoeuvring are chosen properly, we can use these metamodels to calculate the ship manoeuvring performance instead of CFD simulations and model tests in the preliminary ship design stage and also can obtain high fitting precision calculation result of manoeuvring performance in the time-consuming multidisciplinary ship design optimization.

Table 5 The MRE comparison for the five manoeuvring criteria(Unit:\%)

\begin{tabular}{c|c|c|c|c|c|c|c|c}
\hline \multirow{2}{*}{$\begin{array}{c}\text { Manoeuvring } \\
\text { criteria }\end{array}$} & \multicolumn{4}{|c|}{ Case 1 } & \multicolumn{4}{c}{ Case 2 } \\
\cline { 2 - 9 } & ANN & SVR & $\begin{array}{c}\text { SPL- } \\
\text { SVR }\end{array}$ & $\begin{array}{c}\boldsymbol{V} \text {-SPL } \\
\text {-SVR }\end{array}$ & ANN & SVR & $\begin{array}{c}\text { SPL- } \\
\text { SVR }\end{array}$ & $\begin{array}{c}v \text {-SPL } \\
\text {-SVR }\end{array}$ \\
\hline Advance & 7.73 & 5.46 & 3.97 & 3.08 & 7.43 & 6.11 & 4.85 & 3.43 \\
Tactical diameter & 8.37 & 6.51 & 4.80 & 3.27 & 7.00 & 4.98 & 3.75 & 2.83 \\
Transfer & 8.63 & 6.01 & 4.31 & 3.10 & 8.02 & 6.15 & 4.53 & 3.11 \\
\hline
\end{tabular}




\begin{tabular}{|l|l|l|l|l|l|l|l|l}
\hline $10^{\circ} / 10^{\circ}$ first overshoot angle & 8.30 & 6.28 & 4.45 & 3.27 & 7.50 & 5.58 & 4.48 & 3.12 \\
$20^{\circ} / 20^{\circ}$ first overshoot angle & 8.21 & 5.97 & 4.73 & 3.34 & 8.05 & 5.79 & 4.61 & 3.63 \\
\hline
\end{tabular}

\section{Conclusions}

The assessment of ship manoeuvring performance is studied in this paper including advance, tactical diameter, transfer, $10^{\circ} / 10^{\circ}$ first overshoot angle and $20^{\circ} / 20^{\circ}$ first overshoot angle. The metamodels for manoeuvring performance, which are established by the new $v$-SPL-SVR algorithm in conjunction with LHS, are employed in place of expensive simulation and analysis codes and these metamodels can be used to evaluate the ship manoeuvring performance efficiently at preliminary design stages of offshore support vessel. Without using computationally expensive methods such as CFD or model tests, the main advantage of this methodology is to provide detailed and realistic operational profiles of ship designs at the early stage of the design process.

As part of the future work, metamodels of ship resistance, seakeeping and manoeuvring can be combined in the framework of Multidisciplinary Design Optimization to improve its convergence efficiency. Multidisciplinary and multiobjective optimization design problems widely exist in the field of ship design, development of effective framework for multidisciplinary and multi-objective optimization problems with uncertainties will be also considered as a future research direction.

\section{Acknowledgments}


The authors wish to thank The Natural Science Foundation of Jiangsu Province of China (Grant No. BK2012696) and the Project funded by the Priority Academic Program Development of Jiangsu Higher Education Institutions (PAPD) for their financial support.

\section{Reference:}

[1] Campana Emilio Fortunato, Fasano Giovanni, Peri Daniele. Penalty function approaches for ship multidisciplinary design optimisation (MDO). European Journal of Industrial Engineering, 2012, 6(6): 765-784.

[2] Tang Zheng-Mao, Xie De, Ma Shi-Hu. Application of multidisciplinary design optimization and multi-objective problem in conceptual design of ship. Journal of Ship Mechanics, 2010, 14(8): 879-886. (In Chinese)

[3] Feng Baiwei, Liu Zuyuan, Zhan Chengsheng, Chang Haichao, Cheng Xide. Development and application of a prototype system to the multidisciplinary design optimization of ships. Proceedings of the 21st International Offshore and Polar Engineering Conference, 2011: 835-838.

[4] Kuang Ling, Jiang Ping, Shao Xinyu. A web services based distributed multidisciplinary design optimization framework to ship design. Proceedings of the 15th International Conference on Computer Supported Cooperative Work in Design, 2011: 362-366.

[5] He Jim, Hannapel Shari,Vlahopoulos Nickolas. Multidisciplinary design optimization of ship hull forms using metamodels. Proceedings of the ASME Design Engineering Technical Conference, 2011, 5: 847-856. 
[6] Xiao Mi, Gao Liang, Shao Xinyu, Qiu Haobo, Jiang Ping. A generalised collaborative optimisation method and its combination with kriging metamodels for engineering design. Journal of Engineering Design, 2012, 23(5): 379-399.

[7] Gorshy Hesham, Chu Xuezheng, Gao Liang,Li Peigen. An approach combined response surface method and particle swarm optimization to ship multidisciplinary design and optimization. IEEE International Conference on Industrial Engineering and Engineering Management, 2009: 1810-1814.

[8] Li Dongqin,Yao Zhenqiu,Guan Yifeng. Improved Multidisciplinary Design Collaborative Optimization for Offshore Supply Vessel. Journal of Jiangsu University of Science and Technology (Natural Science Edition), 2013, 27(1): 10-13.

[9] Li Dongqin, JIANG Zhiyong, YANG Yongxiang. Multidisciplinary and multi-objective design optimization based on adaptive weighted-sum method. Shipbuilding of China, 2012, 53(4): 75-83.

[10] Li Dong-qin, GUAN Yi-feng, LI Yue-yang. Multidisciplinary design collaborative optimization for the Offshore Supply Vessel. Ship Engineering, 2012, 34(6):42-48.

[11] Liu Chang-De, Zhang Hua, Han Yang, Shi Chao. Black-box modeling and prediction of ship maneuverability based on least square support vector machine.Journal of Ship Mechanics, 2013, 17(8): 872-877.

[12] Dongqin Li, Yifeng Guan, Qingfeng Wang and Zhitong Chen. Support vector regression-based multidisciplinary design optimization for ship design. Proceedings of the 31th International Conference on Ocean, Offshore and Arctic Engineering, 
2012, June 10-15, Rio de Janeiro, Brazil.

[13] Schölkopf, B., A. Smola, R. C. Williamson, and P. L. Bartlett. New support vector algorithms. Neural Computation, 2000, 12:1207-1245.

[14] Vapnik, V.N. Universal learning technology: support vector machines. NEC Journal of Advanced Technology, 2005, 2 (2), 137-144.

[15] IMO Resolution A.751 (18). Interim Standards for Ship Manoeuvrability, 1993.

\section{Author biographies}

Dongqin $\mathrm{Li}$ is an associate professor of ship and ocean engineering, Jiangsu University of Science and Technology (JUST). Her current research interests include ship resistance and manoeuvring performance, multidisciplinary ship design optimization and hydrodynamic numerical methods such as CFD.

Philip A. Wilson is a professor of ship dynamics at the University of Southampton. His current research interests include seakeeping, ship manoeuvring, control of surface following ships together with autonomous underwater vehicle design and operation.

Zhiyong Jiang is a professor of ship and ocean engineering, Jiangsu University of Science and Technology (JUST). His current research interests include ship advanced manufacturing technology, digital and computer application and integrated manufacturing and software systems. 